\title{
Human Resource Motivation, a Necessity Dictated by the Actual Condition of the Market and the Future: A study Performed in the Albanian Banking Sector
}

\author{
PhD. Albana Kacollja
}

PhD. Teuta Balliu

Prof. As. Dr Imelda Sejdini

\begin{abstract}
The human resource management is a basic function which affects the objectives achievement not only on business field, but also on the other spheres of the human activity. The purpose of this paper is to study the involvement and motivation of employees in the organization environment. In order to realize the purpose of this paper, we have analyzed the actual evaluation system of employees in the banking sector and the link among the motivation programs and the satisfaction in the work place. We have raised two hypotheses: $\mathrm{H} 1$ : Employees of different hierarchical levels are satisfied with their current motivation programs, and $\mathrm{H} 2$ : Both female and male employees think that the organization helps them balance their private life with their work life. The primary data are collected through a questionnaire. Hypotheses are tested using the Kolmogrov-Smirnoff test. We used SPSS for data analyzing. From the analyses it results that for some employees the immediate monetary rewards are more important, while for some others the relationship with colleagues and leaders, the work conditions, the work challenge and the opportunities for career growth are more important. We concluded that only male employees manage to balance their work live with private life. As a conclusion we can say that nowadays we need new motivation techniques, mainly for female employees, in order to create a balance among their personal life and their work life. We recommended new programs that can be implemented in business organizations, such as cultural activities, flexible working hours, entertainment activities during trainings and seminars, programs for how employees can better balance their personal life with their job, employee involvement in decision making, and motivation through improving communication and presentation skills.
\end{abstract}

Keywords: Motive, satisfaction, monetary rewards, non-monetary rewards

\section{Introduction}

Nowadays, when there is a significant tendency toward globalization, motivation has become a dominant element in the context of economic and social development, and the clear identification of what we consider as "knowledge society" introduces new challenges toward businesses and their management. In order to increase the chances of success through effective feedback, it is important to stress that everybody and especially the managers of each sector should work more in order to understand better these challenges. Tony Hsieh, CEO of Zappo company, when tries to highlight the importance of the employees, adds that:-"If I am very effective, I can have an innovative idea per day; if I listen to employees I will have 1000 ideas per day". The explanation of the question "why do people work" serves as a way to stimulate the career discussion. The professional career includes an evolution of job activities and positions that people try and experience through their job performance over time, and the attitudes, knowledge and skills they develop throughout their life (Ferrari, 2010). The people's career development helps us to understand better their job context and to determine the most appropriate routes to reward them by including the economic and social status of employees. As a result, the individual perception of employees in relation to development of their career paths can influence their job satisfaction and performance. The findings of another study show us that the employees perform their job effectively if they work to achieve their clear objectives and if the rewards include salaries, promotions, and social recognition (Sekkiou, L et Blondin, L, 1995). The degree of job satisfaction is important for people if the desire for nice and effective job conditions is not only a personal desire, but also a desire to win the respect of the other people within the organization (Pereti, 2004-2005). Informing the employees, team work and getting employees feedback are some of the practices that can help in the creation of an 
environment that guarantees the chance of participation and motivation. All these elements help the organization to structure better the human resource practices and to motivate employees to have a higher performance.

\subsection{Job satisfaction}

Different researchers have defined the job satisfaction in different ways. The phrase "job satisfaction" was brought to the attention by Hoppock (1935) who explored 32 studies on job satisfaction conducted before 1933, and observed that job satisfaction is a physiological combination and dependents on the environmental circumstances affecting employees to conclude whether or not they are satisfied with their job (Hoppock, 1935). This demonstrates that there is a variety of variables which affects job satisfaction, as monetary and non-monetary reward. The job satisfaction is a desirable condition or a positive emotional that results from somebody's job evaluation or from experiences in the work places (Tom Lupton, Dan Gowler, 1989). In other words, job satisfaction explains what makes people love their job, what elements of their duties makes them happy, or what makes them not to abandon their employment. Job satisfaction is attributed not only to one factor, but to a lot of factors and it changes under the effect of the importance that each factor has at different people. (Jonson, November 1969, ). Researchers have also argued that rewards offered by the organizations can have a strong impact on employees' attitudes toward their job and on the organization too (Armstrong, 2002). Based on two theories rewards are either internal or not, and influence the level of employees' satisfaction with their job (Brunero, Volume XXXIII, No. 4, 2002). Different employers have different expectations regarding their salary and job rewards (Daniel llgen, Jack Fedelman, 1993). A lot of companies use different techniques, such as polls, in order to find out which are employees expectations and perceptions about their jobs (Ferrari, 2010). Job satisfaction is positively related to salary itself, but it is also positively related to the average salary of all the other employees, within the same sector or department (Wright, 2004).

One of the most demanding dimensions of job satisfaction is "Job Descriptive Index" (JDI). JDI is a questionnaire which measures itself five basic aspects of job satisfaction (Gregson, 1991) which are; job in itself, the second aspect has to do with the supervisor, the third with collaborators, the fourth with the salary, and the final aspect is the promotion.

\subsection{Work motivation and types of reward}

Motivation is the element that is closely related to employee's job satisfaction. These two elements are positively correlated with each-other. Motivation is an individual phenomenon and the purpose of motivation theories is to predict behavior. It is associated with action, with internal and external factors which influence certain actions (Mitchell, T.R. \& Lason, J.R., 1987). Motivation is not the behavior itself and of course it is not performance. Related to this, Mitchell proposed his definition of motivation. According to him motivation is the degree to which an individual desires and chooses to engage in a certain behavior. It is important for managers to know the elements that motivate their employees in order to use these elements effectively and to create a win-win situation for parties, meaning employees and organizations. Reward in a broader sense relates to employees salaries for the work done as well as other benefits they receive from the organizations. Actually the word reward reflects a more flexible treatment. In today perspective the reward includes not only all the above mentioned, but also non-financial aspects of motivation applied in a contemporary human resource context. It is often assumed that motivation in the work place is closely related to the salary. Salaries are not the only motive and sometimes do not act at all as such. The managers should motivate the employees by taking into consideration both the employee and organization needs. Such rewarding forms indicate that the employer is appreciating the employees. Reward is usually among the first factors that employees take into consideration when they start a new job. It is important to consider the rewarding way of the organization, because employees more than their salary see if they are valued for what they have done or do. Salary is an important element in motivating employees and this is mainly true for countries with conditions and economy like Albania. Studies in the field of human resources show that employees are most likely to overestimate the importance of the salary. This explains why salary is an important source of motivation. However, it should be noted that salary is not equally important in all situations. If studies are conducted by analyzing different variables, such as the impact of financial rewards on productivity, salary do not rank among the first elements. The salary ranks sixth and after that comes security and appreciation (P.Latham, 2006).

\section{Methodology}

The purpose of this paper is to study the involvement and motivation of employees in the work environment. As its objectives we mention analyzing the current programs for the involvement of different employees and identifying new motivating techniques for employees. In order to realize the purpose of this paper we have raised two hypotheses, as follows: 
H1. Employees of different hierarchical levels are satisfied with their current motivation programs.

H2. Both female and male employees think that the organization helps them balance their private life with their work life.

Hypotheses are tested using the The Kolmogrov-Smirnoff test with a confidence level of 95\%. In this work, we used both descriptive and exploring methods. The study is carried out through a questionnaire designed specifically for it. The questionnaire contains 16 questions divided into three sections. To carry out this research, the questionnaires were distributed to 170 employees of various financial institutions of different hierarchical levels, 125 of them have been filled. It should be emphasized that the statistical program SSPS was used for the data analyses.

\section{Analysis of the Human Resource Management in the Albania Banking Sector}

Training and development is one of the strategic factors in creating qualified staff whose level of expertise and professionalism contributes to a higher financial performance for the organization. For this reason, second level banks in Albania offer training packages and staff training courses, based on a preliminary agreement between the employee, the supervisor and the human resources department. Banks rely on the principle that a dedicated and motivated staff is a competitive advantage. Such an advantage cannot be easily copied and without it the majority of corporate initiatives become difficult and even impossible.

\subsection{The elements of compensation}

Two are the main elements of salaries in financial institutions, basic salary and variable salary. Basic salary represents gross income, excluding bonuses and other additional benefits. It is administered based on salary levels, which are based on rank structure, living standards in a country, and market data. The salary structure is generally comprised of 16 ranks or levels. Each rank is presented by a segment which has an average and a maximum stretch which is roughly equivalent to the average market standard for similar positions and shows the maximum level for average performance employees. The maximum point of the segment represents the maximum level of payment for employees with the highest performance. Let's skip on the second element, the variable salary or as called bonus and incentive schemes. Banks, where possible, set a variable salary rate for their employees, which differs between front office and back office personnel. The variable payment rate is no higher than $35 \%$ of the monthly base salary for sales functions and $25 \%$ of the monthly base salary for business support functions. The salary variable is provided through incentive schemes and the year-end bonus. Incentive schemes apply to all sales positions as well as other non-selling positions whose work consists of measurable indicators. These schemes are consistent across all segments of business, with no more than 5 (five) top performance indicators ranked by priority. The bonus, which represents the percentage of the monthly base salary, relates to the percentage of achievement of the target. The right to the benefit bonus generally begins with reaching 80 percent of the target and ends with reaching 130 percent. Employees, who have an average annual performance score of over 130 percent of the target, are part of a special incentive scheme. The following table reflects the bonus policy in one of the commerce banks.

Table 1: Bonus policy examples

\begin{tabular}{|c|c|}
\hline Average annual achievement & Special bonuses \\
\hline $131 \%-149 \%$ & 1 salary \\
\hline $150 \%-199 \%$ & 2 salaries \\
\hline $200 \%$ and above & 3 salaries \\
\hline
\end{tabular}

Source: RBAL Human Resources Manual

\subsection{Performance and bonus}

Performance evaluation is done using a five-step rating, excellent-5, exceeds forecasts-4, reaches forecasts-3, needs improvement-2 and does not reach predictions-1. Employees are eligible for promotion and salary increase when their final performance score is above the 3.5. Employee performance consists of an 80 percent annual assessment of objectives/targets set for each position and 20 percent are competences. Competences that account for 20 percent of total employee performance relate to technical-professional skills, quality of work and productivity, customer focus, sale skills, interpersonal skills and teamwork as well as integrity and trust. 


\section{Data Analysis}

We founded out that for more than $50 \%$ of the employees the reward is a neutral element, which does not affect either positively or negatively in their motivation. This is related to external factors or explained by the fact that people who are looking for a job pay more attention to the salary while employed people are motivated by other non-monetary factors. Employees feel motivated by supervisors and managers. This is reinforced in the second section of questions when more than $68 \%$ of employees generally respond positively to their level of encouragement by managers and their reliance on the performance of their duties. In this case we can conclude that for employees it is important to have other non-monetary elements that influence the achievement of objectives by bringing motivation and satisfaction to them. A very important element is the perception and positive feelings that employees have about opportunities on career growth and their sense of being valued for their contribution to the company. This is a very important factor, as the satisfaction and the appreciation can provide not only more positive results, but also long-term security to the company. However, there is dissatisfaction among the balance between family and professional life. Over $50 \%$ of respondents say that it is difficult to balance work life with the personal one. In subsequent studies the questionnaire may be accompanied by other questions to analyze whether there are any influences from other external factors. It should be emphasized that time management in a more effective way and accurate assignment of tasks and roles is also of a great importance. From the analysis of one of the open questions, it was noted that the importance of high level of collaboration between peers and team work is increasing. New programs that can be implemented in business organizations, from the proposals of respondents relate to; cultural activities, flexible working hours, entertainment activities during trainings and seminars, organization of meetings focused on the improvement or enhancement of employee self-confidence, team work, creating programs for how employees to balance better their personal life with their job, employee involvement in decision making, and motivation through improving communication and presentation skills.

Most important is the fact that employees, around $78 \%$ of them, can recommend the company as employment opportunities to their acquaintances. When employees feel good at work, they are inclined to share this pleasure with others.

In this part of the analysis we can refer to the confirmation of hypotheses raised for this paper. Thus, for the proof of the first hypothesis we have as follows.

$\mathrm{H1}$ : Employees of different hierarchical levels are satisfied with the current motivation programs.

Table 2: The Kolmogrov-Smirnoff test was used to test the satisfaction of non-managerial employees with the current motivation programs.

\begin{tabular}{ccccccc}
\hline Ratings & $\begin{array}{c}\text { Observed } \\
\text { number }\end{array}$ & $\begin{array}{c}\text { Observed } \\
\text { frequency }\end{array}$ & Cumulative & $\begin{array}{c}\text { Null } \\
\text { Proportion }\end{array}$ & Cumulative & Difference \\
\hline 1 & 19 & 0.2289 & 0.2289 & 0.25 & 0.25 & 0.021 \\
2 & 42 & 0.5060 & 0.7349 & 0.25 & 0.50 & 0.234 \\
3 & 18 & 0.2168 & 0.9517 & 0.25 & 0.75 & 0.208 \\
4 & 4 & 0.0483 & 1 & 0.25 & 1 & 0.000 \\
\hline
\end{tabular}

Source: Survey data

Table 3: The Kolmogrov-Smirnoff test was used to test the satisfaction of managers with the current motivation programs.

\begin{tabular}{ccccccc}
\hline Ratings & $\begin{array}{c}\text { Observed } \\
\text { number }\end{array}$ & $\begin{array}{c}\text { Observed } \\
\text { frequency }\end{array}$ & Cumulative & $\begin{array}{c}\text { Null } \\
\text { Proportion }\end{array}$ & Cumulative & Difference \\
\hline 1 & 22 & 0.5238 & 0.5238 & 0.25 & 0.25 & 0.247 \\
2 & 15 & 0.3571 & 0.8809 & 0.25 & 0.50 & 0.372 \\
3 & 3 & 0.0714 & 0.9523 & 0.25 & 0.75 & 0.179 \\
\hline
\end{tabular}




\begin{tabular}{lllllll}
\hline 4 & 2 & 0.0477 & 1 & 0.25 & 1 & 0.000 \\
\hline
\end{tabular}

(Sample $(\mathrm{N})=125$, and the significance level of the data is 5 percent)

Note : (i) Largest absolute difference D1 $=0.234$; D2 $=0.372$; (ii) Significance Level $=5$ percent; (iii) Critical Value $=1.38 / \sqrt{ } n=1.38 / \sqrt{ }(125)=0.1234$

As can be seen from the tables, the highest values of absolute differences are greater than the critical value 0.1234 . In these conditions, we conclude that the hypothesis $\mathrm{H} 1$ stands. Employees, despite their level in managerial hierarchy, feel satisfied.

Second hypothesis $\mathrm{H} 2$ : female employees and male employees are able to balance their personal life with their work life.

Table 4: The Kolmogrov-Smirnoff test was used to test the balancing of personal life with that at work by female employees.

\begin{tabular}{ccccccc}
\hline Ratings & $\begin{array}{c}\text { Observed } \\
\text { number }\end{array}$ & $\begin{array}{c}\text { Observed } \\
\text { frequency }\end{array}$ & Cumulative & $\begin{array}{c}\text { Null } \\
\text { Proportion }\end{array}$ & Cumulative & Difference \\
\hline 1 & 65 & 0.7222 & 0.7222 & 0.333 & 0.333 & 0.121 \\
2 & 18 & 0.2000 & 0.9222 & 0.333 & 0.666 & 0.104 \\
3 & 7 & 0.0778 & 1 & 0.333 & 1 & 0.000 \\
\hline
\end{tabular}

Table 5: The Kolmogrov-Smirnoff test was used to test the balancing of personal life with that at work by male employees.

\begin{tabular}{ccccccc}
\hline Ratings & $\begin{array}{c}\text { Observed } \\
\text { number }\end{array}$ & $\begin{array}{c}\text { Observed } \\
\text { frequency }\end{array}$ & Cumulative & $\begin{array}{c}\text { Null } \\
\text { Proportion }\end{array}$ & Cumulative & Difference \\
\hline 1 & 30 & 0.8571 & 0.8571 & 0.333 & 0.333 & $\mathbf{0 . 5 2 1}$ \\
2 & 4 & 0.1142 & 0.9713 & 0.333 & 0.666 & 0.332 \\
3 & 1 & 0.0287 & 1 & 0.333 & 1 & 0.000 \\
\hline
\end{tabular}

(Sample $(\mathrm{N})=125$, and the significance level of the data is 5 percent)

Note : (i) Largest absolute difference D1 $=0.372 ; \mathrm{D} 2=0.521$

(ii) Significance Level $=5$ percent

(iii) Critical Value $=1.36 / \sqrt{ } n=1.36 / \sqrt{ }(125)=0.1234$

The test was carried out for $a=5$ percent. The absolute largest differences are $=0.121$ and D2 $=0.521$, not both of these values are greater than $\mathrm{c}$ (critical value). Thus we conclude that only male workers manage to balance their lives at work with personal life, $\mathrm{H} 2$ is not proven.

\section{Conclusions and Recommendations}

Motivation and employee satisfaction continue to be important elements for the organizations. The success of a business organization is related to the way in which employees behaves and do their work. Managers should take into consideration the factors that motivate their employees. This is a really delicate process as the motivation elements vary from an employee to another. For some of them, the salary and immediate rewards are more important, for others the relationship with colleagues and superiors, working conditions, challenging work, and career opportunities are more important. Development and refinement of a model that will be based on a recruiting system, integration, training, performance assessment, promotion, motivation, and career development is very important. Albanian companies increasingly need to 
adopt advanced managerial practices because if they neglect today's developments this means higher costs in the future. The most motivated employees are those who like their job, feel good in their work place, and with their work conditions.

We found that the main motivating factor was not the salary, but other non-monetary factors. Based on literature, this can be explained by the fact that job seekers consider the salary as the most important incentives, one employed they achieve motivation and pleasure at work through other non-monetary elements. The data analyze has highlighted other elements that need to be study, such as the importance of time management and a good work- life balance.

In this paper, an important element relates to the fact that most part of employees is willing to recommend the company as an employment opportunity to their relatives. This is an indirect element, which shows the employee satisfaction at work. Employees largely appreciated challenging work, delegated responsibilities, promotion, and group activities. All of these factors are considered important for employees' motivation. Employees support new motivational programs or techniques, which could bring higher productivity at work. This paper also concluded that only male employees manage to balance their life at work with their personal life while. New motivational techniques should be applied primarily to female employees in order to balance their personal life with that at work.

\section{References}

[1] Armstrong, M. (2002). Employee Reward. London: CIPD House.

[2] Brunero, J. S. (Volume XXXIII, No. 4, 2002). Evolution, altruism and "internal reward" explanations. The philosophical forum , 413-424.

[3] Daniel Ilgen, Jack Fedelman. (1993). Performance Appraisal; A process Focus; Research in organizational Behavior. Columbia University, Vol 5, 144-162.

[4] Ferrari, F. (2010, November 22). Work Performance = Competence $x$ Motivation. A two-side model for Human Resources Management. Munich Personal RePEc Archive , pp. 50-63.

[5] Gregson. (1991). The separate constructs of communication satisfaction and job . Educational \& Psychological Measurement .

[6] Hoppock, R. (1935). Job satisfaction. New York and London: Harper and Brothers.

[7] Jonson, H. .. ( November 1969, ). Minimum Wage Laws: A General Equilibrium Analysis. Canadian Journal of Economies, Vol. 2, , 599-604.

[8] Mitchell, T.R. \& Lason, J.R. (1987). People in organization. 3rd ed. New York: McGraw-Hill.

[9] P.Latham, G. (2006). Work Motivation. Los Angelos: Sage.

[10] Pereti, J. M. (2004-2005). Resources Humanist; 9-eme edition. Paris: ED Vuiber.

[11] Sekkiou, L et Blondin, L. (1995). Passion : ressources humaines. Montréal, Canada: Les Éditions 4L Inc.

[12] Tom Lupton, Dan Gowler. (1989). Selecting a wage payment system. London: Kogan Page.

[13] Wright, A. (2004). Reward Management in Context. London: CIPD Kogan Page. 